\title{
Early sarcomatous changes in Paget's disease of bone
}

\author{
E. TAPP \\ M.D. \\ Senior Registrar in Morbid Anatomy, Manchester Royal Infirmary \\ From the Department of Pathology, University of Manchester
}

\begin{abstract}
SARComa is a well-recognized complication of Paget's disease of bone and surgeons are constantly on the alert for malignant changes in this disease (Lake, 1951; Poretta, Dahlin \& Janes, 1957; Barry, 1961 ; Price, 1962). The case which is the subject of the present report has some unusual features which are of interest from both the clinical and pathological points of view particularly as the sarcoma appears to be in an early stage of development.
\end{abstract}

\section{Case report}

The patient, a retired female nurse aged 89 years, was admitted to Sefton General Hospital, Liverpool, with a history of swelling of the right knee for 2 months. She was known to have had Paget's disease of bone for some years.

On examination there was a mass in the lower part of the thigh posteriorly, but it was difficult to determine whether the tumour was arising from the soft tissues or from the femur. Radiographs showed a soft-tissue swelling which had displaced the popliteal artery. There did not appear to be any erosion of the bone (Fig. 1). A mid-thigh amputation was carried out and the patient made an uneventful recovery except for a short attack of jaundice which was attributed to the administration of chlorpromazine.

It is now 2 years since the operation and the patient is alive and without clinical or radiological evidence of metastases.

\section{Pathology}

Macroscopic appearances. There was extensive Paget's disease of the tibia and femur with marked widening of the cortex in both bones and anterior bowing of the tibia. The most significant changes, however, were present at the lower end of the femur and in the adjacent soft tissues (Fig. 2).

The medullary cavity in the distal $6 \mathrm{~cm}$ of this bone was obliterated by islands of dense, homogeneous, white tissue surrounded by softer, grey tissue which contained spicules of calcified material.

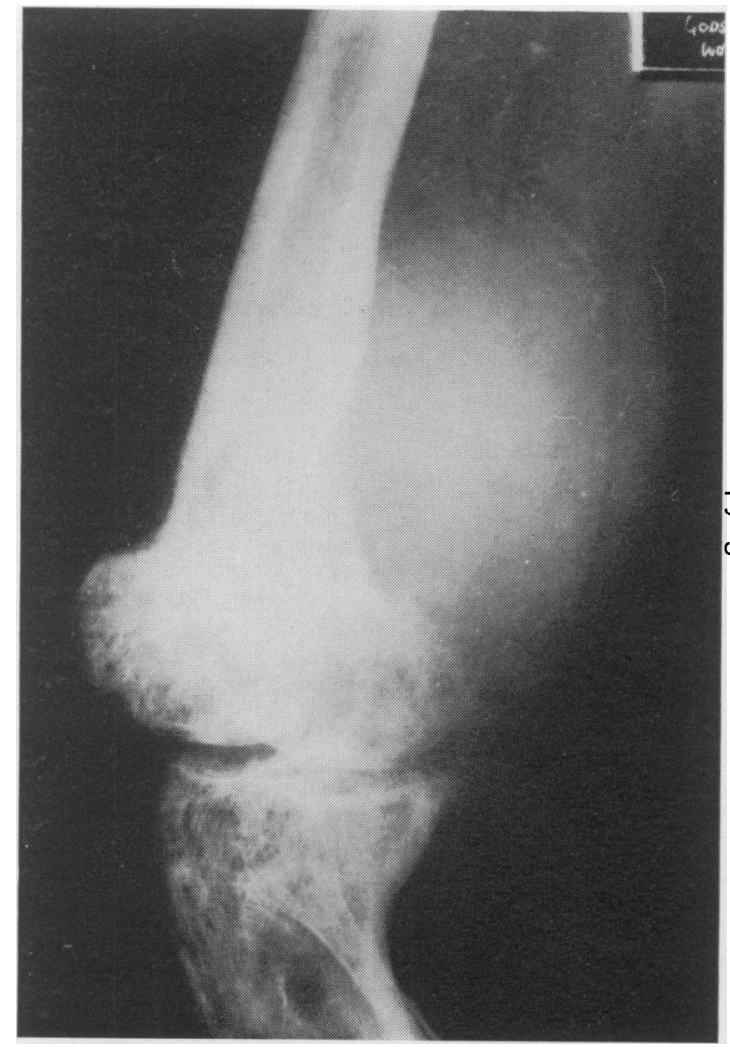

FIG. 1. The popliteal artery shows calcification in its wall and is displaced posteriorly by the tumour.

Proximal to this region there was a cyst, which occupied the medullary cavity and had eroded the cortical bone so that the latter was thinned in this region. The cyst was lined by shaggy chocolatecoloured material and contained blood clot. The blood clot extended out through a crack in the cortical bone and was continuous with a large haematoma in the soft tissues. The popliteal artery was displaced posteriorly by the latter and was closely adherent to it ; there was, however, no communication between the artery and the haematoma. 


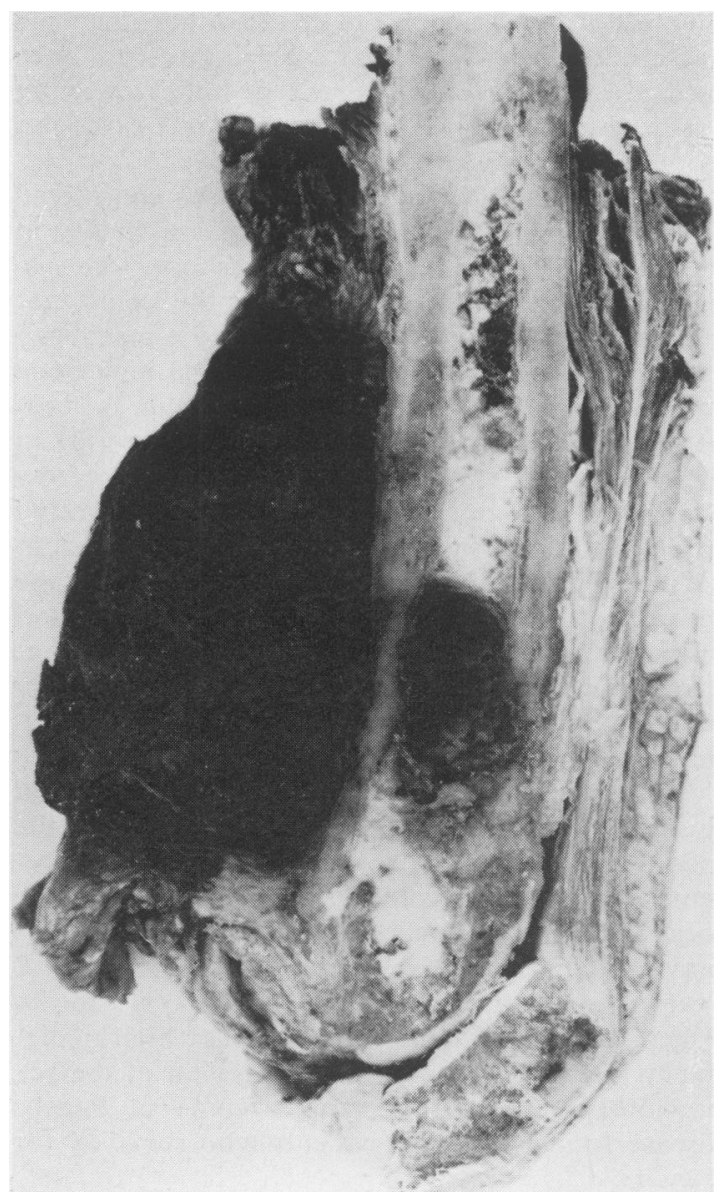

Fig. 2. There is a large haematoma in the soft tissues and this communicates with a blood-filled cyst in the medullary cavity of the bone through a crack in the cortex. The medullary cavity distal to the cyst is obliterated by a mixture of white and grey tissue. $\times 0.4$.

The medullary cavity between the cyst and the site of amputation was narrowed by the cortical thickening but contained normal fatty marrow.

Microscopic appearances. Histological sections confirmed the presence of typical Paget's disease of bone in the cortex, the normal cortical bone being replaced by a dense lamellar bone with an irregular arrangement of the lamellae, poor Haversian system formation and cement lines which showed the typical mosaic pattern.

In the medullary cavity a number of other abnormal changes were present. The grey material seen macroscopically was found to consist of two types of tissues. The part nearest to the articular cartilage contained fairly large bone trabeculae along the edges of which there was evidence of both bone formation and resorption. The marrow spaces between these trabeculae contained vascular fibrous tissue which had an infiltration of lymphocytes and plasma cells. The remainder of the grey tissue consisted of fatty bone marrow infiltrated with large pleomorphic cells. These cells had a small amount of pale eosinophilic cytoplasm and large nuclei of irregular shape and size. The latter had a stippled chromatin pattern and prominent nucleoli but only occasional mitoses were seen (Fig. 3). The degree to which the marrow was infiltrated with these cells varied, in some places there were only small groups lying between fat cells, in others they completely replaced the marrow. Immature, coarse-fibred bone was present amongst these cells and in some parts formed trabeculae which enclosed small groups of fat cells.

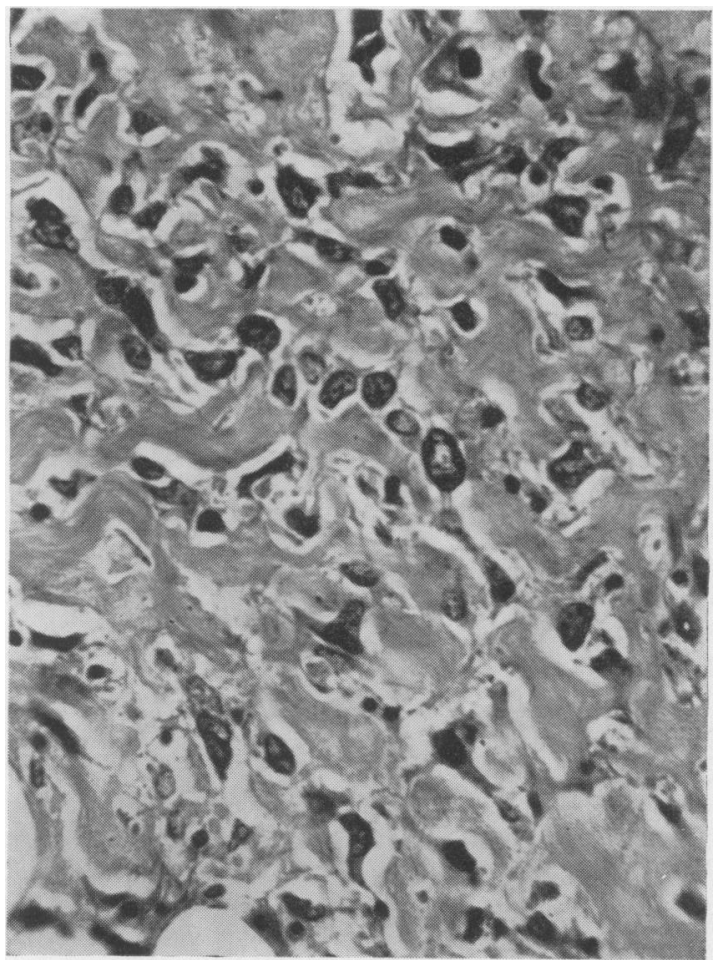

Fig. 3. A high power view of some of the large pleomorphic cells. H \& E, $\times 400$.

The dense white material observed macroscopically consisted chiefly of necrotic tissue. This showed all the patterns described in the previous paragraph but was for the most part completely acellular with only occasional pyknotic nuclei in some areas. Active osteoclastic resorption was seen at the edge of the necrotic area (Fig. 4).

The cyst wall consisted of vascular granulation tissue in which there were macrophages, some containing haemosiderin and others lipid. There was 


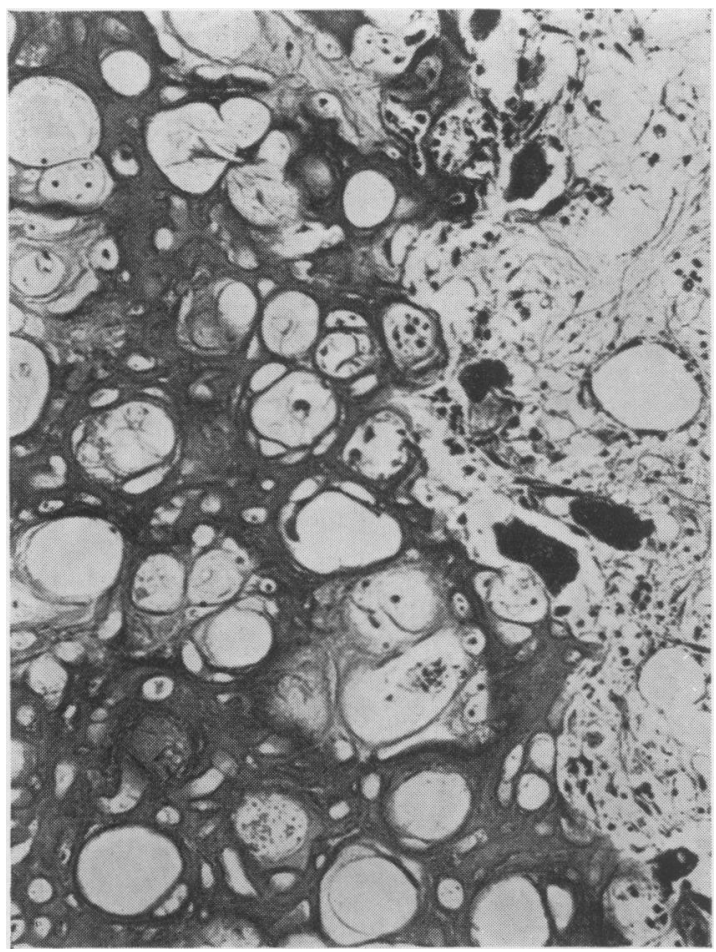

Fig. 4. Many osteoclasts are seen along the edge of the necrotic area. H \& E, $\times 150$.

no evidence of the large pleomorphic cells in the wall nor in the region where the cyst was in communication with the haematoma in the soft tissues.

\section{Discussion}

Clinically this lesion provided some difficulties in diagnosis. The radiographs supported the clinical impression that it was a soft tissue tumour without signs of bony involvement. An amputation without a preliminary biopsy was performed on this evidence and it was only later that pathological examination revealed the unusual features of the case.

The pathological basis for the clinical picture appears to be the bone cyst but the origin of the latter is not clear. Jaffe (1933) suggested that cystic spaces in the bone in Paget's disease may arise 'from liquifaction of the connective tissue and bone in small areas in which haemorrhagic or anemic necrosis has occurred'. It is possible that such a mechanism was responsible in the present case since as we shall see later there is evidence of an ischaemic necrosis of the tumour tissue. On the other hand, the marrow contains many thin-walled blood vessels in Paget's disease and rupture of one of these could give rise to haemorrhage. In the case under discussion the organizing blood clot in the wall of the cyst suggests that such haemorrhage might well have been responsible. The cyst once formed appears to have weakened the overlying cortex leading to a partial fracture and extension of the haemorrhage into the soft tissues.

There is no evidence that the lesions considered so far are directly related to a malignant change in the Paget's disease process. It was only on systematic histological examination of the lesion that evidence of sarcoma was detected in the medullary cavity distal to the cyst. Much of the new bone formation seen in this part of the femur is compatible with that found in Paget's disease and in these areas there are the associated marrow changes of increased vascularity, fibrosis and round cell infiltration. In some parts, however, osteoblastic pleomorphic cells appear to be invading the fat cells of the marrow. This is not a feature found in uncomplicated Paget's disease and indicates that a neoplastic change has taken place. It probably represents one of the earliest recognizable sarco. matous changes in Paget's disease of bone.

The early nature of the lesion is also reflected in the fact that the lesion is confined entirely to the medullary cavity. Due to the unusual clinical presentation the leg was amputated before extensive local spread of the sarcoma could occur and this may account for the absence of metastases after 2 years in spite of the fact that sarcomas arising in Paget's disease of bone are usually of high malignancy. Poretta et al. (1957) in his review of the 128 previously reported cases of sarcoma in Paget's disease found only five patients who survived for 2 years.

No explanation can be offered for the fact that much of the tumour tissue is necrotic despite the small size of the lesion. It had not been subjected to radiotherapy. The density of the new bone formation around the fat cells with very little interstitial tissue does suggest, however, that its peculiarly sclerotic nature may have resulted in the obliteration of its blood supply.

\section{Summary}

A case is presented in which early sarcomatous changes at the lower end of the femur were found in association with Paget's disease of bone. A large, soft tissue haematoma arising from a bone cyst close to the tumour led to surgical treatment of the neoplasm at an early stage.

\section{Acknowledgments}

Thanks are due to F. C. Dwyer, M.Ch.(Orth)., F.R.C.S., for permission to publish the clinical details of the case and to Dr H. A. Sissons for his opinion on the nature of the lesion. This case was studied when the author was Lecturer in Orthopaedic Pathology, University of Liverpool. 


\section{References}

BARRY, H.C. (1961) Sarcoma in Paget's disease of bone in Australia. J. Bone Jt Surg. 43A, 1122.

JAFFe, H.L. (1933) Paget's disease of bone. Arch. Path. 15, 83.

LAKE, M. (1951) Studies of Paget's disease (osteitis deformans). J. Bone Jt Surg. 33B, 323.
Porretta, C.A., Dahlin, D.C. \& JANes, J.M. (1957) Sarcoma in Paget's disease of bone. J. Bone Jt Surg. 39A, 1314.

Price, C.H.G. (1962) The incidence of osteogenic sarcoma in south-west England and its relationship to Paget's disease of bone. J. Bone Jt Surg. 44B, 366.

\section{Renal tubular acidosis and cirrhosis}

\author{
Paul M. SMith \\ M.B., M.R.C.P.
}

\author{
J. E. Middleton \\ B.M., M.R.C.P.
}

Consultant Chemical Pathologist

\author{
ROGER WILLIAMS* \\ M.D., M.R.C.P.
}

Formerly Consultant Physician

\section{Southampton General Hospital}

THE CHARACTERISTIC biochemical disturbance of renal tubular acidosis is a sustained metabolic acidosis with hyperchloraemia, together with an inability to excrete urine of a $\mathrm{pH}$ lower than 6.0 in response to an ammonium chloride load (Seldin \& Wilson, 1966). In many patients there are also a number of associated abnormalities, such as hypokalaemia, osteomalacia and nephrocalcinosis. Primary forms of the disease are described, and the syndrome can also occur as part of the clinical picture of the Fanconi syndrome. In the latter condition cirrhosis has been described (McCune, Mason \& Clarke, 1943; Stowers \& Dent, 1947) but we have been unable to find any previous reports of cirrhosis associated with renal tubular acidosis.

\section{Case report}

A housewife, born in 1931, had three attacks of pleurisy. The third caused her to be admitted to hospital in 1957, where she was found to have a slightly enlarged liver and a spleen palpable $9 \mathrm{~cm}$ below the costal margin. She was not jaundiced, but a few spider naevi were noticed on her hands and wrists. Liver function tests: serum bilirubin, $0.7 \mathrm{mg} / 100 \mathrm{ml}$; alkaline phosphatase, 13 K.A. units $/ 100 \mathrm{ml}$; zinc turbidity, 40 units; thymol turbidity, 12 units; serum albumin, $3.0 \mathrm{~g} / 100 \mathrm{ml}$; serum globulin, $4.8 \mathrm{~g} / 100 \mathrm{ml}$; with an electrophoretic strip showing a diffuse increase in $\gamma$-globulin. A liver biopsy showed small nodules of apparently normal parenchymal cells, separated by interstitial tissue containing a moderate infiltration of chronic inflammatory cells. Further tests performed at the Hammersmith Hospital (Professor Sheila Sherlock) included a barium meal

\footnotetext{
*Present address: King's College Hospital, London, S.E.5.
}

which revealed no oesophageal varices, and a splenic venogram which showed a patent portal vein with small collaterals passing to the left gastric and umbilical veins. The intrasplenic pressure was $14 \mathrm{mmHg}$. Unfortunately no measurement of her plasma electrolytes was made at this time.

Two years later, in 1959, she was admitted to hospital with the signs and symptoms of hypokalaemia. She was drowsy, with pain and weakness in her limbs, and polyuria. Plasma potassium levels on two occasions were 2.7 and $3.2 \mathrm{mEq} / 1$. More detailed investigations showed her to have renal tubular acidosis, with plasma electrolytes of: chloride, $124 \mathrm{mEq} / 1$; bicarbonate, $14 \mathrm{mEq} / 1$; and sodium, $143 \mathrm{mEq} / 1$. Urinary potassium excretion was $72 \mathrm{mEq} / 24 \mathrm{hr}$ on a day when plasma potassium was $2.8 \mathrm{mEq} / 1$. After receiving $3 \mathrm{~g}$ of ammonium chloride daily for 6 days, the minimum urine $\mathrm{pH}$ obtained was 6.8. Serum calcium, $9.2 \mathrm{mg} / 100 \mathrm{ml}$; urinary calcium excretion, $328 \mathrm{mg} / 24 \mathrm{hr}$; creatinine clearance, $108 \mathrm{ml} / \mathrm{min}$. Straight X-ray of the abdomen: renal shadows normal. A catheter specimen of urine contained a trace of protein and only occasional pus cells. However, a renal biopsy (Professor H. E. de Wardener) revealed a chronic patchy inflammatory cell infiltrate, associated with ischaemic changes in the glomeruli, suggestive of pyelonephritis. She was discharged on potassium bicarbonate and citrate supplements, to which were later added rotating antibiotics.

During the next 5 years there was little change in her condition. In April 1966 she stopped taking potassium supplements and was readmitted, semiconscious and dehydrated, with marked muscular weakness. Plasma electrolyte levels were similar to 